\title{
Preconceito e bullying na constituição de uma professora de libras: experiências de uma surda
}

\author{
Saionara Figueiredo Santos* \\ Susana Inês Molon ${ }^{* *}$
}

\section{Resumo}

Este artigo aborda a questão do preconceito e do bullying na constituição de uma professora surda de Língua Brasileira de Sinais (Libras) do Rio Grande do Sul. Faz parte de uma pesquisa de mestrado, de cunho qualitativo, fundamentada na abordagem sócio-histórica, cuja coleta de dados foi realizada por meio de entrevistas semiestruturadas com uma professora surda, bem como pelo uso de recursos imagéticos, o que possibilitou o surgimento de narrativas de vida do sujeito pesquisado. Para análise de dados, foi empregada a técnica da análise de conteúdo, sendo que a categoria principal refere-se ao preconceito. A professora surda afirmou que sua trajetória de vida foi marcada pelo preconceito e por episódios de bullying. As narrativas demonstraram a necessidade de aprofundamento na discussão dessas duas temáticas, enfatizando três unidades de análise que lhes correspondem: a) o preconceito e o bullying dentro da escola; b) preconceito ouvinte-surdo; e c) preconceito surdo-surdo. Os resultados evidenciaram que o preconceito na escola e na relação ouvinte-surdo vem sendo discutido na sociedade, porém o preconceito surdo-surdo precisa ser enfrentado e debatido, assim como o audismo e a surdofobia. A própria constituição da professora surda ajuda a compreender melhor o histórico de sofrimento e superaçáo envolto na Educação de Surdos, e também como isso afeta o processo de constituição do sujeito inserido em uma sociedade de ouvintes.

Palavras-chave: Preconceito; Bullying; Surdo.

* Doutoranda em Estudos da Tradução pela Universidade Federal de Santa Catarina, Florianópolis, Santa Catarina, Brasil.

** Professora doutora da Universidade Federal do Rio Grande, Rio Grande, Rio Grande do Sul, Brasil. 


\section{Prejudice and bullying in the constitution of a teacher: a deaf woman experiences}

\section{Abstract}

This article approaches the issue of prejudice and bullying in the constitution of a deaf woman, a Brazilian Sign Language teacher of Rio Grande do Sul. It is part of a qualitative research based on the socio-historical approach, which used semi-structured interviews with a deaf teacher as well as imagery resources, what made the emergence of life narratives of the research subject possible. For data analysis, we used the technique of content analysis, being prejudice the main category. The deaf teacher, through her positioning and her experiences, said that her life story was marked by prejudice and bullying episodes. The narratives demonstrated the need for deepening these two themes, emphasizing three analysis units to which they relate: a) prejudice and bullying within the school; b) hearing-deaf prejudice; and c) deaf-deaf prejudice. The results showed that prejudice in school and in deaf-hearing relationship has been addressed by society, but deaf and deaf bias needs to be addressed and discussed, as well as Audism and Surdophobia. The very constitution of the deaf teacher provides a better understanding on the history of suffering and overcoming, wrapped around Deaf Education, and also on how it affects the process of constituting the subject inserted into a hearing society.

Keywords: Prejudice; Bullying; Deaf people.

\section{Introdução}

A falta de um melhor preparo para lidar com as diferenças na sociedade tem demonstrado a nossa incapacidade perante determinadas situaçóes, consideradas ainda verdadeiros tabus em pleno século XXI. Entre elas, destaca-se o preconceito, seja ele de qualquer ordem.

Uma perspectiva de entendimento sobre preconceito expressa uma relação em que sujeitos diferentes podem desvalorizar ou negar a identidade do outro. Segundo Britto da Motta (2007, p. 131), o preconceito ocupa um espaço bem definido nas relaçôes sociais, pois são elas que "modelam e dão o tom das identidades coletivas e individuais". Qualquer indivíduo pode apropriar-se dos estereótipos culturais da sociedade e modificá-los segundo suas preferências (CROCHIK, 2006). Entretanto, nem todos conseguem ser conscientes destas diferenças e multiplicidades sociais que compóem a sociedade, muito menos controlar aspectos envolvidos nos relacionamentos sociais que ecoam dessa diversidade.

No caso dos surdos, sofrer preconceito é uma das características de sua história. Há marcas culturais, provenientes de uma grande parcela da sociedade, que identificam os surdos como deficientes, incapazes. A partir desse entendimento de surdez, todo tipo de violência física e simbólica foi exercido, "passando por extermínio, reclusão em casa, proibição do uso da língua de sinais, segregação em escolas 
especiais" (WITKOSKI, 2009, p. 565), até a atual proposta bilíngue, que se foca nas questôes linguísticas, nem sempre contemplando transformações nas relações culturais e sociais.

Nessa perspectiva, este $\operatorname{artigo}^{1}$ visa a explanar sobre um fenômeno que emerge do preconceito, o bullying, no contexto das relaçôes sociais de sujeitos surdos ${ }^{2}$. Lopes Neto (2005) explica sobre o bullying ao dizer que este compreende qualquer tipo de atividade agressiva, repetitiva e intencional que causa dor e angústia à vítima. Assim, segundo o autor, preconceito é diferente de bullying, já que preconceito é uma opção de não gostar de determinada cultura por algum motivo supostamente negativo, tendo consequências práticas ou não. O bullying caracteriza-se como a violência em si, sendo causada por preconceito ou não.

Refletindo sobre ser surdo neste conturbado contexto de intolerância, compartilha-se das ideias de Skliar (1997) quando salienta a raia divisória no processo de entender sobre ser surdo sem o manto do preconceito, ou seja: entender o surdo como um ser diferente e como deficiente, com uma concepção antropológica e não clínica. Ao contrário da concepção clínica, que prevê um tratamento, que define ser surdo como uma doença (um problema a ser tratado), a visão antropológica e social define ser surdo como uma singularização do indivíduo, uma maneira diferente de ver o mundo e entendê-lo.

Sobre essa visão singular dos surdos, há um discurso atual significativo que objetiva acabar com os estereótipos dados a eles. Como Perlin (1998, p. 58) ressalta, esse discurso "continua na busca de poder e autonomia" dos surdos, poder este muitas vezes manifestado por sua cultura surda, sendo a língua de sinais, por exemplo, um artefato cultural dos surdos. Só que as experiências visuais vão mais além da língua. Referem-se à identificação dos surdos tanto individualmente como em grupo, e como estes conseguem reproduzir e significar muitas coisas.

O atual modelo de "normatividade", exprimido por Skliar (2000, p. 11), é a referência representada pelo entendimento da sociedade sobre o surdo; um "modelo econômico político concêntrico", que promove uma teoria e uma práxis de globalização a partir de uma pretensa homogeneidade humana inexistente (WITKOSKI, 2009). No entanto, conforme a autora defende, esta "padronizaçáo" normativa sustenta-se pelos diferentes preconceitos existentes na atual sociedade como expressão máxima do etnocentrismo.

Seguindo essa linha de raciocínio, é importante pensar os desafios que permearam a trajetória de cada um dos surdos frente a padróes de normalidade impostos pela sociedade, no que diz respeito a aceitar a sua diferença e ser aceito como diferente e não como deficiente. Assim, faz-se necessário considerar o preconceito e o bullying nas diversas fases da vida de ser surdo, bem como esse preconceito se reflete na subjetividade dos surdos.

Este estudo traz excertos de narrativas de uma professora surda, nos quais ela relata casos de preconceito e bullying durante sua trajetória, bem como a sua maneira de lidar com eles. 


\section{Procedimentos metodológicos}

Os pressupostos metodológicos desta pesquisa estão fundamentados na abordagem sócio-histórica (MOLON, 2008; FREITAS, 2002), que coloca em evidência a constituição do sujeito e as relações entre estes, num processo de subjetivação focado na singularidade humana. O procedimento metodológico utilizado para a coleta de dados foi a entrevista semiestruturada. Considerando que a professora surda entrevistada é usuária da Libras, os encontros foram gravados em vídeo e depois traduzidos da Libras para o Português. Para facilitar a interação entre pesquisador e pesquisado, e o aprofundamento das reflexóes nas narrativas de vida do sujeito pesquisado, foram utilizados recursos imagéticos, que promoveram o detalhamento das narrativas. Para a análise de dados, foi empregada a técnica da análise de conteúdo (FRANCO, 2007), na qual emergiu, como categoria principal, o preconceito.

\section{Constituição da professora surda: o singular na história}

Para melhor contextualizar as falas da entrevistada, busca-se, neste tópico, contar um pouco de sua história de vida, seus desafios e sua superação. Trata-se de uma professora de Libras com 29 anos de idade. Ela nasceu surda, fez sessóes de fonoaudiologia quando criança, dos cinco aos 12 anos de idade, conseguindo oralizar de maneira satisfatória. Iniciou sua vida escolar numa instituição só para surdos, com aulas em Libras; ali foi que percebeu que era surda e teve contato com esta língua.

Com 12 anos, por motivos familiares, teve de deixar a escola de surdos e ir para uma escola inclusiva, onde não havia intérprete de Libras e todos falavam Português. Teve de se adaptar a esta situação até os 17 anos. Nesse meio tempo, não teve mais contato com a comunidade surda, nem com a Libras. Entretanto, aos 17 anos, reencontrou a comunidade surda, o que ela considera, segundo suas próprias palavras, "o dia mais feliz de sua vida". Este é um exemplo de que existe um "clamor pela coletividade surda" (QUADROS, 2003), em que os surdos querem a convivência com seus semelhantes.

Em sua trajetória de vida, enfrentou preconceito e bullying. Além disso, não pôde decidir sobre qual comunidade permanecer na sua adolescência, náo pôde usar sua língua materna, tendo de encarar a postura da sociedade, no que se refere a ser surda. Ainda assim, ela conseguiu superar todas as suas dificuldades e seguir a carreira que desejou - professora de Libras -, do mesmo modo que a primeira surda adulta professora, com a qual teve contato na escola de surdos, ressaltando a importância da representatividade atuante desde os anos iniciais de vida dos surdos.

A seguir, apresentam-se alguns trechos das narrativas da surda entrevistada, que demonstram aspectos relacionados ao preconceito e ao bullying em sua vida.

\section{O preconceito e o bullying dentro da escola}

Ficavam falando que eu era surda, que eu não sabia de nada, essas coisas. Eu me sentia diminuída e sempre ficava calada. Eu ia para as aulas, copiava tudo, sempre calada, mas tinha duas amigas que me ajudavam, só as duas, mais ninguém da sala. Eu me sentia 
muito mal. [...] eu lembro de uma vez que eu sofri preconceito na escola da parte de colegas, uma ocasião na escola de $2^{\circ}$ grau, meus colegas me chamavam de retardada, burra, etc. pelas minhas costas [...] odiava essa escola, odiava minha vida... me dava vontade de sumir do mapa.

A partir do fragmento acima, é possível perceber os sentimentos de menosprezo e opressão emanados dos xingamentos dos colegas. A visão preconceituosa que menospreza os surdos influenciou o comportamento (proposital ou por desconhecimento de causa) dos colegas da surda em questão. Tomasini (2008, p. 114) argumenta que "todos os que não se encaixam num perfil estabelecido são diferenciados". No caso da entrevistada, ela não se sentia pertencente a um grupo miscigenado que não respeitava sua identidade e língua. Nesse sentido, o senso comum pode desencadear o preconceito do "outro", "o diferente, desviando dos processos normais de um determinado tipo de sociedade um indivíduo não-normal, não-normativo" (TOMASINI, 2008, p. 115).

Ela também menciona esse preconceito de maneira aprofundada, citando a palavra Bullying em um dos seus comentários.

[...] eu sofria preconceito na escola (ensino médio) essa é a pior da minha vida, sofri bullying. Eu sofri bullying em várias situaçóes, eu lembro algumas delas... todos os dias sofria, todos os dias era mesma coisa, me zombavam. Me dava vontade de fugir, não aguentava mais. Mas eu me esforçava para continuar frequentando a escola. Fui estudiosa, guerreira [...] tudo se repetia, todos os dias. A inclusão foi uma "merda", de verdade. No ensino médio, os adolescentes sempre aprontavam algo comigo, o que era diferente das crianças que eu convivia na educação infantil [...] percebi e aprendi como é ser adolescente com os ouvintes, não foi fácil.

Embora ela tenha usado a palavra bullying, nem todos os surdos conhecem o seu significado (SILVA, 2010). A partir do que ela relata - "prefiro não ver o preconceito nem ver o bullying" - conclui-se que as práticas de bullying por ela sofridas tiveram como propulsor o preconceito pelo fato de ser surda, como ela mesma declara - "acho que ninguém merece sofrer bullying, nem os surdos nem ninguém merece". Assim, no decorrer da análise, usa-se mais a palavra bullying, que foi retirada das falas da entrevistada, sendo este fenômeno causado pelo preconceito vivenciado pela professora surda.

O sentimento de frustração proporcionado por ocasiôes de bullying, na tentativa ou fracasso em seguir determinado padrão social, pode ter efeito direto sobre a integridade psicológica de quem o sofre. É no campo das relaçôes sociais e da subjetividade que o surdo elabora a imagem que tem de si mesmo, podendo adquirir uma identidade socialmente construída com interesses de outras pessoas e não de si próprio.

A entrevistada ainda mencionou que "...os colegas me chamavam de retardada, burra..." e "...todos os dias sofria, todos os dias a mesma coisa, me zombavam...", e isso é considerado bullying direto verbal, conforme Rodrigues (2010) caracteriza. Ao 
continuar dissertando sobre a temática, o autor afirma que esse tipo de bullying é feito de ofensas verbais e que os responsáveis não imaginam as consequências a longo prazo na vida da vítima; consequências psicológicas, que podem acompanhar o sujeito pela vida inteira, tal como narrado pela entrevistada.

[...] porque bullying é um trauma, fica para sempre gravado na mente de quem sofre. Qualquer pessoa que sofre bullying não consegue esquecer fácil o que passou, isso ajuda na formação de quem ela é, ela pode se tornar mais compreensiva ou pode ser uma pessoa amargurada mais traumatizada, podendo facilmente desistir de estudar ou trabalhar.

Minha autoestima ficou baixa, lá embaixo, vivi num inferno, por longos 8 anos [...] preferia náo ver o preconceito nem ver o bullying, por isso estava vendada, não queria saber o que acontecia nem saber o que eles diziam de mim. Me escondia e fugia!

Ainda acerca de como ela se sentia com essa situação, sobre os efeitos na vida dela, pode-se notar o efeito sobre a sua autoestima na adolescência. Pelo fato de usar termos como "foi uma época muito difícil", "Eu me sentia muito mal", “... odiava essa escola, odiava minha vida... me dava vontade de sumir do mapa", "eu não aguentava mais viver...", percebe-se quanta influência os comentários maldosos de colegas tiveram na sua vida. Tomasini (2008, p. 117) explica que os indivíduos estigmatizados passam a ser objeto de "depreciaçáo de seu comportamento na totalidade de seu ser, sendo considerados sob o ângulo de suas limitaçóes”. A visão voltada ao distanciamento do diferente, da reduçáo da identidade social de um surdo pautada num "atributo indesejável" que este possui, pode colocá-lo no ostracismo, tanto por parte dos colegas quanto dos professores.

Lopes Neto (2005) classifica as vítimas do bullying como pessoas que não têm recursos ou habilidades para reagir ou acabar com isso. No caso da entrevistada, a sua timidez, o fato de ela ser surda, nenhum de seus colegas saber a Libras, de não ter muitos amigos (ela também relata que só duas meninas a ajudavam no cotidiano de sala de aula) corroboraram sua inércia, em termos de reação. Lopes Neto (2005, p. 167) comenta que "a rejeição às diferenças é um fato descrito como de grande importância na ocorrência de bullying", sendo esta também a situação que a professora vivenciou: o principal motivo do bullying foi o fato de ser surda. O autor complementa que, na maioria das vezes, as diferenças são motivos para a agressão (verbal ou física).

Vale mencionar, ainda, que para a entrevistada era muito mais difícil contatar os superiores (direçáo e responsáveis) acerca do que se passava dentro da sala de aula devido à barreira linguística, já que não havia intérpretes dentro da escola. A falta do intérprete é um agravante no caso de alunos surdos, já que estes dependem desses profissionais para fazer a mediação linguística junto a uma grande maioria não fluente na língua. E, somado a isto, falta preparação pedagógica para receber os alunos surdos e lidar com todas as nuances que isso traz para a escola.

Por fim, ressalta-se que, acerca do bullying e de suas implicaçôes, a prevenção é imperativa. Para tanto, escola, professores, pais, comunidade e alunos precisam 
refletir, construindo mecanismos de rechaço a estas atitudes, com base no esclarecimento e no respeito às diferenças. Além disso, é necessário instrumentalizar (ainda que num primeiro momento, no âmbito das ideias) as pessoas para agirem quando tal fato negativo se manifeste. É importante que, desde os primeiros anos, haja a discussão sobre a relação diferença-preconceito e a imagem e racionalização do outro, seja este surdo ou portador de qualquer outra diferença (BANDEIRA e BATISTA, 2002).

Em alguns trechos, a entrevistada especifica estes mecanismos voltados às relaçóes dentro da comunidade surda, o que também será analisado a seguir.

\title{
Preconceito ouvinte-surdo
}

\begin{abstract}
Mas há também o preconceito com surdos, eu sofri muito preconceito, queria me esconder [...] fugir da minha vida sofrida, fugir da minha identidade, fugir do mundo dos ouvintes que eu não aguentava mais viver. [...] Não queria ser vista como coitada na sala de aula, queria ser igual a todos, mas nem todos me viam assim porque achavam que os surdos eram incapazes, nos encaravam como deficientes. Eles nem sabem como os surdos são, não se interessam em saber a vida, cultura e identidade surda, nem mesmo se interessam em aprender a Libras...[...] sempre mostramos e explicamos tudo aos ouvintes que dificilmente acreditam em nós.
\end{abstract}

No que se refere às representaçôes que os ouvintes têm dos surdos, é observável na fala da entrevistada que nem sempre essas representaçóes demonstram quem realmente os surdos são. A representação do surdo, em grande maioria, é sempre veiculada à deficiência, à incompetência, como já explanado anteriormente. Esse tipo de constatação se dá principalmente depois de o surdo começar a ter contato com os ouvintes preconceituosos, como a própria entrevistada afirmou, quando disse "eu comecei a sentir esse preconceito quando me mudei pra escola de ouvintes", evidenciando que existe violência nas relações sociais que explicitam a opressão e a dicotomia. Skliar (1998) explica que manter os binarismos eficiência/deficiência, normalidade/ anormalidade coloca sempre o surdo no lado ruim, sendo este sempre percebido como o oposto (e ruim) do ser ouvinte, não aceitando isso como uma diferença específica. Além disso, há uma relação histórica de poder ouvinte-surdo, além de discursos constantes que naturalizam o surdo como ser inferior. $\mathrm{O}$ surdo se sente dessa maneira e é essa forma que reflete a internalização de suas experiências em diferentes coletivos (MARIN e GOES, 2006).

Nessa perspectiva de incapacidades, surge o termo audismo. Esse termo foi criado pelo professor surdo Tom Humphries, na década de 1970. Burad \& Humphries (2010) explicam que, por mais que esse termo ainda não esteja nos dicionários, ainda assim é usado para fazer referência à discriminação arbitrária dada aos surdos no decorrer da história, bem como engloba todas as consequências e experiências negativas que deterioram a autoestima do surdo, individualmente ou como grupo. É como se uníssemos o bullying movido pelo preconceito, devido ao fato de a entrevistada ser surda, e que isso tivesse uma denominaçáo geral. Assim, entende-se adequado o uso de tal terminologia. 
Lane (1993) também usa o termo "audismo" de Humphries. Ela fala dos profissionais de ensino chamando-os de "audistas", já que estes pensam a educação para surdos como uma educação que os inferioriza. Esse conceito busca tentar definir o olhar de preconceito para com o sujeito surdo, mistificando o surdo como alguém dependente e digno de pena. Segundo ela, os surdos que sofrem o audismo - e acrescente-se, os surdos que aceitam o audismo - vão sim encontrar dificuldades, tornando-se realmente dependentes. É importante, portanto, retomar essa discussão acerca do audismo, já que muitas vezes os surdos recebem tratamentos misericordiosos erroneamente, gerando uma reflexão pejorativa sobre ser surdo.

Silva, Campelo e Novena (2012) falam de outro termo, denominado surdofobia. Segundo eles, esse termo é mais convincente no plano das desigualdades sociais. Eles defendem e definem esse termo como:

Um tipo de exclusão ou aversão ao sujeito surdo, atribuindo ao mesmo o espaço dos "outsiders", o espaço do gueto. A título de maior elucidação, apontemos que o audismo e a surdofobia, embora tenham conceitos que se entrecruzam, bem como a existência do primeiro pode levar à existência do segundo, trata-se de dois conceitos distintos. (p. 4).

Um exemplo dado por esses autores ajuda a diferenciar os dois termos audismo e surdofobia. Por exemplo, quando um surdo não pode participar de um processo seletivo por alegaçóes de que um surdo não pode ser capaz de cumprir as tarefas para ele delegadas, essa aversão ao surdo é entendida como surdofobia. Por outro lado, se permitem a participação de um surdo e ele é aprovado nesse processo seletivo, mas são-lhes dadas funçôes "mais leves", em que se exige menos, agindo com a "misericórdia”, que já foi citada, isso é audismo.

No contexto escolar, esses conceitos também acontecem. A entrevistada concorda com essa afirmação, quando afirma que foi tratada com desrespeito e preconceito pelos ouvintes de sua turma. Isso pode ser observado no trecho abaixo, em que ela assim se expressa:

Pois não é só colocar a pessoa na sala de aula, muito precisa ser feito, os professores precisam ser treinados. (...). Não queria ser vista como coitada na sala de aula... queria ser igual a todos, mas nem todos me viam assim porque achavam os surdos incapazes, são deficientes.

Desse modo, pode-se afirmar que há, da parte da maioria dos professores, falta de preparo para receber os surdos, podendo ocasionar um tratamento ora "privilegiado e humanitário" em demasia, colocando o surdo no status de coitado (audismo), ora evitando inserir os surdos em determinados espaços e atividades escolares, por achar que eles não conseguirão acompanhá-las (surdofobia).

Percebe-se, ainda, que todo o histórico de bullying e preconceito não a afetou a ponto de impedi-la de buscar e acreditar numa possível evoluçáo de si mesma e das relaçóes nas quais estava inserida. Usando palavras como "mas pouco a pouco o mundo dos ouvintes se abre pra nós, pouco a pouco ele nos aceitam como diferentes, 
passam a nos respeitar e nos dar acessibilidade", a entrevistada reconhece os pequenos avanços na aceitaçáo dos surdos em suas peculiaridades, além das conquistas dos surdos como comunidade, havendo enfrentamento na busca de visibilidade. Encarar o futuro com uma perspectiva otimista e positiva é o que se percebe nos avanços conquistados pela comunidade surda. O movimento em comunidade tenta enfrentar as atribuições identitárias negativas, "opondo, ao sentimento de vergonha e do silêncio que tinha sido construído através de sociabilidades baseadas na negação da alteridade, o sentimento de orgulho" (BANDEIRA e BATISTA, 2002, p. 125), revelando uma luta contra a outorga social negativa à diferença do outro.

Nem sempre o exercício da alteridade consegue ser feito por todos em determinada comunidade, fazendo-nos partir para outra temática também levantada pela entrevistada.

\section{Preconceito surdo-surdo}

Este tópico emergiu das falas da entrevistada. Nas suas contribuiçóes acerca das relaçóes sociais, ela critica o destratamento ou a falta de união entre a maioria da comunidade surda usuária da Libras e da maioria dos surdos oralizados ou implantados, que náo fazem uso de nenhuma língua de sinais. Além disso, ela denuncia que nem todos os surdos que usam a Libras conseguem pertencer de fato a uma comunidade surda academizada. Segundo ela, quanto menor a fluência na Libras e o nível de estudo, menos incluídos estes indivíduos se sentem.

Ela relata que: "É um tipo de preconceito com outros surdos, é polêmico porque os surdos lutam contra o preconceito, mas dentro da comunidade surda há preconceito, acho engraçado até". Há uma segregação que a professora percebe, reproduzindo o modelo de preconceito no qual repudiam. E ela continua: "náo tenho preconceito com nenhum desses tipos, porque eu já sofri preconceito, sei como é difícil, não quero reproduzir esse modelo, cada um decide o que fazer na sua vida e o que fazer".

No caso de surdos implantados, vê-se nas falas da entrevistada o preconceito envolto. Quando ela diz "Do tipo, ver um surdo implantado e falar - Nossa ele fez o implante coclear, como ele pôde fazer isso?!", esse tipo de comentário demonstra uma atitude intolerante quanto às decisóes particulares de alguns surdos que desejam fazer o implante coclear.

Sobre a constituição da identidade surda, a entrevistada diferencia um surdo que nasceu surdo e aceita a Libras e um surdo que nasceu ouvinte e posteriormente aprende a Libras. Ela comenta que:

Alguns surdos acham que a identidade dele nasceu no momento em que ele ficou surdo, mas não é assim. Ele tem todo um passado ouvinte que o constitui, não perdeu tudo isso no momento que ficou surdo. [...] no caso do surdo que nasceu ouvinte, ele possui identidade ouvinte. Posteriormente é que ele vai assumir ser surdo, seu novo idioma, usar o trabalho das intérpretes de Libras, posteriormente que ele pode fazer isso. Ou pode nunca se aceitar surdo. 
Quando ela fala em se aceitar surdo, percebe-se que quer dizer aceitar sua língua, sua identidade e cultura surda. E observa-se que, para a maioria dos surdos, aceitar a Libras como o idioma dos surdos, aceitar a cultura surda e a identidade surda, bem como todos os caminhos que os perpassam, são vistos como obrigação de todo e qualquer surdo. Porém, isso não é tão simples e nem sempre acontece.

Entende-se que, para a maioria dos surdos que participam da comunidade surda, quando o surdo opta por não usar a Libras, ou por aceitar a cirurgia de implante coclear para conseguir ouvir, ele está rejeitando sua identidade, cultura e língua de sinais. Segundo as falas da entrevistada, há uma desconfiança dos surdos usuários da Libras, participantes da comunidade surda, para com os surdos oralizados, implantados, que preferem não utilizar a Libras e não pertencerem à comunidade surda.

Rezende (2010) descreve essa atitude como um enfrentamento contra uma norma que minimiza os desvios da surdez, em que o implante coclear genocida as línguas de sinais e as "subalterniza como segunda categoria; uma norma do padrão soberano ouvinte, que nos administra a fim de equiparar os surdos aos normais, aos ouvintes, entre outros tantos que tentam nos impor e nos assujeitar" (REZENDE, 2010, p. 154). Ao mesmo tempo, no final de seu estudo, a autora percebe que o enfrentamento é necessário; concomitantemente, este precisa também ser equilibrado. Apesar de nomear o avanço tecnológico voltado ao campo dos surdos como uma "parafernália na vida e na comunidade surda" (p. 159), a autora reconhece que não há como negá-lo, embora este seja uma tecnologia para a normalização surda (à qual a autora se opóe). Ela continua:

Mas podemos, sim, negociar com essa tecnologia. Um espaço de negociação para que as crianças implantadas sejam bilíngues. Negociar para que as crianças implantadas possam ter a riqueza e a beleza da língua de sinais e da língua oral, no caso, a língua portuguesa; duas línguas que andam juntas sem que uma subalterne a outra. (REZENDE, 2010, p. 159).

É preciso mencionar que os surdos precisam pedir pela acessibilidade (conforme suas escolhas de língua e cultura), além do respeito pela diversidade dentro da comunidade dos surdos. É o mesmo respeito que se exige à diversidade de ouvintes. O respeito precisa existir, seja qual for seu nível linguístico (dos usuários da Libras) ou dos que escolheram náo participar da comunidade surda porque querem ser oralizados e interagir da maneira que entendem que é mais eficaz, ou dos que decidiram fazer o implante coclear por desejo pessoal de ouvir.

Nunes, Dandolini e Souza (2011) complementam que:

Está na hora de ficar claro que nem todos os surdos nasceram assim, que muitos que nasceram com surdez, por diferentes caminhos, voltaram a ouvir; que muitos emudeceram, mas outros se comunicam oralmente sem maiores dificuldades; que entre os brasileiros há analfabetos da língua portuguesa; da mesma forma, entre os surdos, há muitos que desconhecem a Libras e muitos que a dominam sem jamais terem sido surdos. Está na hora de os surdos se conhecerem melhor, de incluir-se a si mesmos em seu grupo.

(NUNES, DANDOLINI e SOUZA, 2011, não paginado). 
Novas pesquisas tentam articular o implante coclear e as línguas de sinais, como por exemplo, Quadros, Cruz e Pizzio (2012), mostrando que algumas crianças surdas com implante parecem ser beneficiadas com o acesso irrestrito à Libras. "A aquisição de uma língua pelos olhos favorece a aquisição da linguagem nestas crianças e favorece um desenvolvimento bilíngue de forma mais apropriada" (QUADROS, CRUZ e PIZZIO, 2012, não paginado).

Obviamente, outras pesquisas precisam ser realizadas, já que é um assunto polêmico e pouco abordado. Em suma, o direito de escolha de cada surdo precisa ser respeitado, sem radicalismos e preconceito. Finaliza-se com a opiniáo da própria entrevistada, que nos faz pensar. Diz ela que: "Acho isso incoerente, todos nós somos surdos, deveríamos estar juntos e não haver esse tipo de preconceito".

\section{Considerações finais}

A professora entrevistada escolheu ser ela mesmo, usuária da Libras. A partir de sua narrativa, foi possível perceber os caminhos tortuosos relativos à sua inclusão educacional. A questão de "aceitar a diferença" já foi superada; o que falta, segundo ela, é a sociedade se preparar para recebê-la e para receber os muitos surdos usuários da língua de sinais imersos na pedagogia inclusiva atualmente. De que modo? Com metodologias pedagógicas que respeitem os surdos como seres que aprendem o conhecimento de maneira diferente dos demais (ouvintes), e que precisam, como qualquer indivíduo, se expressar e ter acesso à informaçáo para, assim, viabilizar a construçáo do conhecimento, sendo este processo destituído de surdofobia e audismo.

Sabe-se que a história do povo surdo já é permeada por evidentes estigmas que evidenciam incompletude e incapacidade. A partir de uma concepçáo de surdez baseada nesses preceitos, todo tipo de violência foi exercido sob esse grupo, desde reclusão em casa, proibição do uso da Língua de Sinais, segregação em escolas especiais, além de "escolas bilíngues" que apenas permitem o uso social da Libras e não privilegiam metodologias que abarquem as necessidades pedagógicas de surdos. Assim, fica evidente que, desde sempre, o leque de preconceito envolve o ser surdo.

Neste artigo, delimitou-se a apenas alguns dos fatos expressos pelas falas de um único sujeito. Nesse sentido, fica evidente a ampla gama de pesquisa aberta para ouvir o que os sujeitos dessa história - os surdos - têm a dizer em suas narrativas de vida.

O desafio atual dos surdos é manter viva a chama da diferença e continuar lutando para conquistar espaços, visibilidade e o direito de poderem ser quem escolheram ser. As escolas bilíngues são o desejo atual dos surdos que usam a Libras e a luta por elas continua. Os surdos que usam a Língua de Sinais continuam a defender e a lutar por uma alfabetização que leve em conta a pedagogia da diferença, ou seja, que respeite o surdo como ser capaz, respeite sua língua, cultura e identidade. E, principalmente, que a Libras seja o primeiro idioma a ser aprendido pelo surdo e, a partir daí ele possa aprender a língua portuguesa e construir outros conhecimentos. 
Além disso, é importante considerar que, assim como a sociedade ouvinte é bastante problemática em vários sentidos (político, econômico, ético, pessoal, etc.), a comunidade surda também se revelou - conforme as falas do sujeito de pesquisa como um espaço de conflito. Náo há ausência de conflitos em nenhum espaço onde indivíduos diferentes entre si convivem e isso também se aplica aos surdos. A existência de preconceito dentro da comunidade surda e na sociedade em geral foi abordada na fala da surda entrevistada, principalmente com surdos oralizados e implantados, assim, algumas posturas precisam ser superadas.

Ao concluir, espera-se que os aspectos aqui explorados, e também aqueles que não o foram - ao menos não suficientemente -, possam servir de estímulo para novas pesquisas, agregando outros diagnósticos e informaçóes, sempre no sentido de buscar o aprimoramento.

\section{Referências}

BANDEIRA, L.; BATISTA, A. S. Preconceito e discriminação como expressōes de violência. Revista Estudos Feministas. Florianópolis, v.10, n.1, p. 119-141, 2002. Disponível em: <http://www.scielo.br/pdf/ref/ v10n1/11632.pdf>. Acesso em 01/09/2015.

BURAD, V. \& HUMPHRIES, S. T. El audismo. Cultura sorda [En línea] Disponível em: <http://www.cultura-sorda.eu/resources/Burad_Audismo-2010.pdf>. Revisado en 20 de enero de 2012.

FRANCO, M. L. P. B. Análise de conteúdo. Brasília: Liber Livro, 2007.

FREITAS, M. T. A. A Abordagem sócio-histórica como orientadora da pesquisa qualitativa. Cadernos de Pesquisa, n. 116, p. 21-39, julho, 2002. Disponível em: <http://www.scielo.br/pdf/cp/n116/14397>.

LANE, H. L'oppression dans les relations entre les professioneles entendants et les sourds de culture. In: HILLION, M.; LABRÈCHE, J.; M. VALLIÈRES, M. (Orgs.) Nouvelles pratiques sociales - Dossier la Surdité. Quebec. Presses de l'Universite du Quebec. v. 6, n. 1, p. 41-56, 1993.

LOPES NETO, A. A. Bullying: comportamento agressivo entre estudantes. Jornal de Pediatria. Rio de Janeiro. v. 81 (5), p.164-172, 2005.

MARIN, C, R; GOES, M, C, R. A experiência de pessoas surdas em esferas de atividade do cotidiano. Cadernos Cedes, Campinas, vol. 26, n. 69, p. 231-249, maio/ago. 2006. Disponível em http://www.cedes.unicamp. br>.

MOLON, S.I. Questốes metodológicas de pesquisa na abordagem sócio-histórica. Informática na Educaçáa: teoria e prática. Porto Alegre, v.11, n.1, p. 56-68, jan./jun. 2008.

NUNES, E. V.; DANDOLINI, G. A. E.; SOUZA, J. A. Uma reflexão sobre acessibilidade e inclusão: adianta adicionar a Língua Brasileira de Sinais a um vídeo, se não houver legendas para deficientes auditivos que não dominam Libras? 17/06/2011. Planeta Educaçáo. Disponível em: <http://www.deficienteciente.com.br/uma -reflexao-sobre-acessibilidade-e-inclusao.html>.

PERLIN, G. Histórias de vida surda: identidades em questão. Dissertação (Mestrado) - Universidade Federal do Rio Grande do Sul, Porto Alegre. 1998. Disponível em: <http://www.porsinal.pt/index.php?ps=artigos\&i$\mathrm{dt}=\operatorname{artc} \& \mathrm{cat}=20 \&$ idart $=153>$.

QUADROS, R. M. de. Educaçáo de surdos: a aquisiçấo da linguagem. Porto Alegre: Artes Médicas, 2003.

QUADROS, R. M. de; CRUZ, C. R.; PIZZIO, A. L. Memória fonológica em crianças bilíngues bimodais e crianças com implante coclear. Revista Virtual de Estudos da Linguagem. v. 10, n. 19, p. 185-201, 2012.

REZENDE, P. L. F. Implante coclear na constituiçấo dos sujeitos surdos. Florianópolis. 2010. 164 f. Tese (Doutorado em Educação) - Universidade Federal de Santa Catarina, UFSC, 2010. Disponível em: <http:// repositorio.ufsc.br/xmlui/bitstream/handle/123456789/94074/281476.pdf?sequence=1\&isAllowed=y>. Acesso em 25 de maio de 2014.

RODRIGUES, J. R. M. Violência velada: um estudo sobre bullying na escola. In Anais do IV seminário nacional sobre educação e inclusão social de pessoas com necessidades especais. Natal, p. 1-11, 2010. 
SILVA, A. B. B. Cartilha: Bullying - justiça nas escolas. $1^{\text {a }}$ ed. Conselho Nacional de Justiça. Brasília, 2010. P. 1-16.

SILVA, J. G.; CAMPELO, L. B. B.; NOVENA, N.P. Desejos e afetividades que não querem calar: o grupo LGBT surdos de Pernambuco. Trabalho apresentado no evento: Pesquisa e Educação na Contemporaneidade: Perspectivas Teórico-Metodológicas, Caruaru, 2012.

SKLIAR, C. Abordagens sócio-antropológicas em educação especial. In: SKLIAR, C. (Org.). Educaçáo e exclusáo: abordagens sócio-antropológicas em educação especial. Porto Alegre: Mediação, 2000. p. 7-20.

SKLIAR, C. Os estudos surdos em educaçăo: problematizando a normalidade. In: SKLIAR, C. A Surdez: um olhar sobre as diferenças. Porto Alegre: Mediaçáo, 1998.

SKLIAR, C. A reestruturação curricular e as políticas educacionais para as diferenças: o caso dos surdos. Identidade social e a construçáo do conhecimento. Porto Alegre: Prefeitura Municipal de Porto Alegre/Secretaria Municipal de Educação, p. 242-281, 1997.

TOMASINI, M. E. A. Expatriação social e a segregação institucional da diferença: reflexôes. In: BIANCHETTI, L., FREIRE, I. M. (Org.). Um olhar sobre a diferença: interação, trabalho e cidadania. Campinas, SP: Papirus, 2008.

WITKOSKI, S. A. Surdez e preconceito: a norma da fala e o mito da leitura da palavra falada. Revista Brasileira de Educaçáo, v. 14, n. 42, set./dez. 2009. Disponível em: <www.scielo.br/pdf/rbedu/v14n42/v14n42a12. pdf>. Acesso em 14 abr. 2015.

\section{Notas}

${ }^{1}$ Este artigo faz parte de um estudo maior, desenvolvido durante o mestrado da primeira autora, sob a orientaçáo da segunda, no Programa de Pós-Graduaçáo em Educaçáo Ambiental, na Universidade Federal do Rio Grande - FURG.

${ }^{2}$ No caso deste estudo, os surdos aqui denominados são usuários da Língua Brasileira de Sinais, doravante Libras.

\section{Correspondência}

Saionara Figueiredo Santos - Instituto Federal de Santa Catarina, Câmpus Palhoça Bilíngue. Rua João Bernadino da Rosa, Cidade Universitária Pedra Branca, CEP: 88137010 - Palhoça, Santa Catarina - Brasil.

E-mail: saionara.figueiredo@gmail.com - susanamolon@vetorial.net

Recebido em 27 de outubro de 2015

Aprovado em 21 de junho de 2016 